Central to most community-bused programs is the goal of improving the community'scapacity to address its own problems. Evaluating changes in community capacity requires contextualized definitions that (1) respect geographic, political, academic, and community perspectives and (2) inclusive evaluation approaches.

\title{
Evaluating Community-Based Health Programs That Seek to Increase Community Capacity
}

\author{
Edith A. Parker, Eugenia Eng, Amy J. Schulz, \\ Barbara A. Israel
}

Critical reflection and new opportunities for funding in the field of public health have given rise to a number of partnership approaches to research and practice (Israel, Schulz, Parker, and Becker, 1998). These approaches, often referred to as community based, have called for increased attention to the complex issues that compromise the health of people living in marginalized Communities; more integration of research and practice; greater community involvement and control; increased sensitivity to and competence in working within diverse cultures; expanded use of both qualitative and quantitative research methods; and more focus on health and quality of life (Israel, Schulz, Parker, and Becker, 1998).

A central tenet of this emphasis on community-based public health research and practice is the importance of building on and enhancing the strengths and problem-solving capacity of communities as an objective of interventions aimed at promoting health and preventing disease. This recognition of the importance of community capacity for health promotion has a long tradition in public health, with explication in the 1940s by South Africans Steuart and his colleagues Kark and Cassel (Trostle, 1986). In Steuart's social change model, increasing Community problem-solving capacity to address barriers to good health is an objective that is as important as improving health status itself (Eng, Salmon, and Mullan, 1992; Steckler, Dawson, Israel, and Eng, 1993; Steuart, 1993; Trostle, 1986). Despite recognition of the role of community capacity in 
health promotion, few attempts to evaluate changes in community capacity have been reported in the literature.

This chapter describes key issues to consider in evaluating community capacity based on four community-based health programs that have included increasing community capacity or a related concept as one of the defined objectives of their program and their subsequent evaluations. Two are programs in rural areas, and the other two are in large urban settings. Three of the four programs target general health, and the fourth program focuses on improving the health of women and children.

\section{Definitions of Community Capacity}

Despite recognition of the relationship of community capacity to health promotion, there is no clear consensus on the operational definition of community capacity. For example, community capacity is often used interchangeably with other, similar concepts such as community competence (Cottrell, 1976; Eng and Parker, 1994; Goeppinger and Baglioni, 1985), sense of community (McMillan and Chavis, 1986), and empowerment (Israel, Checkoway, Schulz, and Zimmerman, 1994; Wallerstein, 1992). Yet all three of these concepts differ from each other. A competent community is defined as one in which the various parts of the community are able to collaborate effectively in identifying the problems and needs of the community, can achieve a working consensus on goals and priorities, can agree on ways and means to implement the agreed-on goal, and can collaborate effectively in the required actions (Cottrell, 1976). Sense of community is defined as opportunities in a community for membership, influence, mutual needs to be met, and shared emotional ties and support. An empowered community is one in which individuals and organizations collectively use their skills and resources to meet their respective needs. Within an empowered community, there are opportunities for citizen participation in decision making and interaction between individuals and organizations. Through this participation and interaction, individuals and organizations support each other, address conflicts within the community, and gain influence and control over the quality of life in their community. An empowered community has the ability to influence decisions and changes in the larger social system (Israel, Checkoway, Schulz, and Zimmerman, 1994).

Given this lack of consensus on the definition of community capacity, the Division of Chronic Disease Control and Community Intervention, Centers for Disease Control and Prevention (CDC), convened a two-day symposium in 1995 as a process for further specifying and clarifying the dimensions that are integral to community capacity (Goodman and others, 1998). The participants represented a wide range of disciplines, including community health development, health education, community psychology, epidemiology, anthropology, political science, and sociology. At the symposium, participants engaged in a series of facilitated discussions around the definition of community capacity, and dimensions of community capacity were identified. Participants were then assigned to work groups that corresponded to each dimension. Over the 
next few months, the work groups researched these dimensions, and their findings were synthesized in an article describing and analyzing the dimensions of community capacity. The dimensions delineated are citizen participation and leadership, skills, resources, social and interorganizational networks, sense of community, understanding of community history, community power, community values, and critical reflection (Goodman and others, 1998).

This definition encompasses many of the constructs others have used in evaluating community capacity and related phenomena. For example, elements of community empowerment can be found in the dimensions of power, values, and critical reflection. In addition, sense of community is listed as a dimension of community capacity (as opposed to its previous conceptualization as a separate but related concept to community capacity). Components of community competence are also included in the dimensions of participation and leadership, skills, and social and interorganizational networks.

This framework for community capacity highlights the challenge for evaluators in seeking a single definition and operationalization of community capacity building. As Goodman and colleagues noted, the dimensions of community capacity in their framework are broad but not exhaustive, and capacity is a construct that has different meanings in different contexts. Some evaluators have suggested that the context of communities is so unique that one operational definition of community capacity is not possible (Eng and Parker, 1994). Others suggest that concepts such as community competence and community empowerment are not dimensions or aspects of community capacity (as suggested in the framework) but very different concepts, which relate directly to the goals of the program or the context of the community in which the program is implemented.

In short, the definition and operationalization of community capacity are still evolving. The purpose of this chapter is not to resolve these defined issues but rather to present examples of community-based health programs that have assessed different dimensions of community capacity and to identify common key lessons learned from each of these evaluation experiences. Each of the case studies described here used a slightly different operationalization of community capacity in evaluating program process, impact, and outcomes.

\section{Case Examples of Evaluations of Programs Seeking to Enhance Community Capacity}

The following section describes the four community health projects and their evaluations that serve as case studies for this chapter.

East Side Village Health Worker Partnership. This is a project of the Detroit Community Academic Urban Research Center, funded by the CDC. Its broad goal is to improve the health of women and children in the targeted area within east side Detroit through the involvement of lay health advisers, referred to as village health workers (VHWs) in this project (Parker, Schulz, Israel, and 
Hollis, 1998). A participatory action research approach is being used to ensure that the lay health adviser model is adapted to the context and setting of this particular urban area. The partnership involves an extensive evaluation research component that uses a single case study design and a combination of quantitative and qualitative data collection methods, including participant observations and field notes of steering committee meetings, VHW training, monthly meetings of VHWs and special events; a seven-hundred-household face-to-face random sample community survey conducted in the first and fifth years of the project; pre-and posttraining assessment of VHWs; focus group interviews with VHWs; in-depth interviews with VHWs, steering committee members, community key informants, health department staff, and agency and community-based organization staff; and documentation records by VHWs and staff.

Aspects of community capacity assessed through the evaluation of the VHW partnership include opportunity for participation, skills and resources available to community members and lay health advisers involved with the project; social and interorganizational networks; sense of community; commitment to community; perceptions of organizational and community influence; and perceptions of shared values. To operationalize these aspects of community capacity in the household survey, evaluators have included measures of a sense of community (McMillan and Chavis, 1986), empowerment (Israel, Checkoway, Schulz, and Zimmerman's perceived control scale, 1994), community competence (items from Eng and Parker's community competence scale, 1994, with items developed based on the work of Warren and Warren, 1977), and social integration and informal social control (measured with a four-item social integration scale and a four-item informal social control scale) (Sampson, Raudenbush, and Earls, 1997). In addition, respondents in the qualitative in-depth interviews are asked about their perceptions of the problem-solving capacity of their neighborhoods.

Partners for Improved Nutrition and Health (PINAH). This program was implemented in 1988 as a five-year collaborative effort by the Freedom from Hunger Foundation, the Mississippi State Department of Health, and the Mississippi Cooperative Extension Agency. The project targeted communities in three small towns in a county in the Mississippi delta. The three overall goals were to improve the health-seeking behaviors of community residents, enhance the problem-solving capacity of local relational communities, and improve outreach and referral patterns of local health and human service agencies. To achieve these goals, PINAH staff recruited and trained lay health advisers from the three communities in basic health information, counseling, and community organization techniques (Eng and Parker, 1994).

The PINAH project also employed a participatory action research approach to evaluation. Four structured data collection instruments were developed to collect quantitative data to assess community competence, interagency referrals, and two separate instruments on community health advisers' (CHA) helping activities with the members of their social networks. Qualita- 
tive data collection methods included individual in-depth and focus group interviews with community health advisers and service providers, parents, teenagers, senior citizens, people helped by the lay health advisers, interagency council members, community residents, respondents to the annual quantitative community competence survey, and PINAH staff.

To assess community competence, PINAH evaluators used Cottrell's community competence construct as a starting point to develop, with community member input, a closed-ended questionnaire. This instrument included items intending to measure Cottrell's eight dimensions of community competence (participation, articulateness, communication, self-other awareness, management of relations with larger society, machinery for facilitating participant interaction, conflict containment and accommodation, and commitment) as well as the added dimension of social support. Qualitative interviews also included questions about perceived changes in these dimensions of community competence.

In 1992, the W. K. Kellogg Foundation launched the four-year, \$16 million Community-Based Public Health Initiative (CBPH) in response to suggestions outlined in the 1988 Institute of Medicine's Report on the Future of Public Health and to concerns about the growing disparity in health status between the have and have-not communities. The CBPH initiative was designed to strengthen linkages between public health education and public health practice by forming formal partnerships among academia, health agencies, and people in communities. To be eligible for the program, each site had to form a consortium consisting of a school or an academic program of public health, at least one other health professions school, one or more communities with serious public health problems, and the local public health agencies of these communities. North Carolina and Michigan were two of the seven national sites funded through this initiative (Brownson, Riley, and Bruce, 1998).

North Carolina Community-Based Public Health Initiative (NC CBPHI). The NC CBPHI consists of four separate county coalitions, each of which is focusing project activities within a community in that county (Parker and others, 1998; Eng and others, 1999). Members of each of the coalitions include, at the minimum, representatives from the University of North Carolina Schools of Public Health and Medicine, the health department of that county, at least one community-based organization, one primary health care center, and representatives from the community with which the coalition is working. Although the specific objectives of each of the four county coalitions differ slightly in wording and in indicators, the coalitions share common objectives:

To increase the problem-solving capacity of the relational community with which the coalition is working

To improve the health status of minority and high-risk populations in selected communities 
To increase the ability of agencies within that county to work with the communities they serve to bring about change

To establish an interorganizational network that will increase collaboration among community service agencies, the university, and community members to serve better the minority or high-risk populations in the communities with which the coalition is working

To improve the skills of School of Public Health faculty and students to work with minority and high-risk populations

To recruit minority youth from the participating county into health-related careers (Eng and others, 1999)

Evaluation of the NC CBPHI employed a multiple case study participatory evaluation design with each county coalition, the overall consortium, and academic partners serving as single cases. Evaluation reports for each of these cases were generated at baseline, Year 2, Year 3, and Year 4 of the project (the final funded year from the Kellogg Foundation). Data sources for these reports included annual in-depth qualitative interviews with coalition members (an average of forty interviews per year for the four coalitions), participant observations of coalition meetings and sponsored events (an average of sixty events across the four coalitions each year), a review of coalition documents, and a health agency survey and survey of School of Public Health faculty that were administered in Years 2 and 4 of the project.

To assess changes in community capacity, the NC CBPHI evaluation focused primarily on changes in the ability of the community partners to participate as full partners in all coalition decisions and activities and to be recognized as equal partners by agency and university coalition partners. For example, the evaluation sought to measure the extent to which community partners were not only at the table but played a key role in driving the goals, objectives, and activities of the coalitions. The evaluation also sought to measure changes in community competence in the communities that were the focus of coalition activities. Qualitative in-depth interviews and focus groups were primarily used to evaluate changes in these aspects of community capacity and community competence. Questions for the interview guides in these interviews were developed based on criteria and indicators jointly developed by the coalition members.

Broome Team of Genesee County, Michigan Community-Based Public Health. The Community-Based Public Health Initiative in Michigan focused activities in Detroit and Flint, Michigan, and was called the Detroit-Genesee County Community-Based Public Health Consortium. The partners in Flint named themselves the Broome Team, in honor of a community leader who had been involved in the early planning of the $\mathrm{CBPH}$ initiative in Flint. Here we focus on the evaluation activities of the Broome Team.

Broome Team partners included representatives from the University of Michigan School of Public Health and the Health Professions and Studies School at the University of Michigan, Flint; the Genesee County Health Department; and the following community-based organizations: Flint Odyssey House, 
Genesee Area Skill Center, Genesee County Community Action Agency, Flint Area Community Economic Development, and Flint Neighborhood Coalition. The two main goals of the Broome Team were to strengthen public health education and practice by linking academic and agency professionals with people from vulnerable neighborhoods and to promote the public's health by enhancing the capacity of community members and community-based organizations. Broome Team used the following evaluation methods:

- Closed-ended questionnaires focusing on the process of the Broome Team meetings

- Monthly reporting forms completed by each of the organizations involved in the Broome Team to document their activities

- A survey of health center staff members conducted in October 1994

- Focus groups conducted with community members who worked with four of the six community based organizations ( $\mathrm{CBOs}$ ) involved with the Broome Team

- Field notes taken at the monthly Broome Team meetings

- In-depth interviews with Broome Team members in Years 1 and 4 of the project

- Follow-up conversations with members of the Broome Team regarding their activities and the relevance of those activities to the goals and objectives of the Broome Team as a whole

In addition, evaluation activities focusing on the School of Public Health, a major partner in the Broome Team, consisted of a faculty survey, field notes at meetings of the community-based public health committee within the school, focus groups with students, a student survey, and in-depth interviews with faculty and students who participated in CBPH activities.

Within the Broome Team, the dimensions of community capacity that were included in the evaluation were citizen participation and leadership; group process (including processes for decision making, resolving differences of opinion, and building trust); participant interaction; decision-making autonomy of organizational representatives to the Broome Team; history with the collaborative group; and perceptions of influences at the individual and organizational levels. These dimensions include aspects of Cottrell's eight dimensions of community competence (Cottrell, 1976), Israel and colleagues' community empowerment (Israel, Checkoway, Schulz, and Zimmerman, 1994), as well as issues identified within the group itself as important aspects of community capacity. Results from the evaluation efforts were used as process indicators within the group and served as discussion tools for members of the Broome Team to examine and address issues related to their collaborative efforts. Over time, these evaluation tools documented evolutions in trust among group members, differences in history with the group (for example, which organizations were able to sustain ongoing involvement with the collaborative and which had less sustained or consistent representation), and differences in perceived decision-making influence within the collaborative body. 


\section{Key Issues to Consider in Evaluating Community Capacity}

The key issues we present are based on our experience with the evaluations of the four community-based health projects just described. Although these principles and methods are presented as distinct items, they are interrelated, and the order in which they are presented is not meant to suggest a ranking of their importance. Finally, we discuss these issues within the context of advocating for the use of multiple types of evaluation activities (process, impact, outcome, and context) when evaluating health promotion programs seeking to enhance community capacity (Israel and others, 1995).

- Evaluation of community capacity should use a broad definition of community that includes political and power considerations as well as the geographic boundaries and relationships of the community. A crucial question facing evaluators of programs attempting to increase community capacity is defining the community. Definitions of community can focus on one or all of the following: geographic elements (an aggregate of individuals residing in a particular place), relational elements (the functions of ties among organizations, neighborhoods, families, and friends), or political elements (the coming together of people to set a political dynamic in motion to transform and act on issues they face) (Heller, 1989; Israel, Checkoway, Schulz, and Zimmerman, 1994; Labonte, 1989; McKnight, 1991). Often programs focus on the first definition of community without considering the second two definitions. Yet consideration of all three of these elements of community can improve understanding of the key factors to focus on in seeking to increase community capacity and evaluate those increases.

Recognition of the political dynamics of a community is especially crucial in community interventions in socially and economically marginalized communities. In operationalizing community capacity, consideration of the political dynamics of that community and how these dynamics affect the health and well-being of those persons involved in the intervention may be particularly useful in identifying the targets of change that the program activities will focus on. For example, in work done with rural communities in Mississippi and North Carolina through the PINAH and CBPHI projects, community residents identified the quality of and access to services as well as access to community facilities as key facilitating factors in enhancing a community's capacity (Parker and Eng, 1995). These residents saw both the quality of services offered and the limited access to services and facilities as grounded in a lack of political clout among these community members and fear of racial integration by the political office-holders in these communities. The PINAH evaluation thus included changes in community service delivery agencies and institutions as part of the desired project outcome of enhanced community competence. To explore these desired changes, qualitative interviews included questions about client satisfaction, access to care, and perceived organizational change in health and social service agencies and questions about changes in the relationships between community members and the power holders within these institutions, 
agencies, and local government. These questions sought to document changes in the political relationships within the community. Qualitative evaluation data suggested that the community health advisers of the PINAH program had contributed to improvements in service accessibility in two of the intervention communities and increased service availability, quality of services, and service utilization in the third intervention community. In addition, these data suggest that relationships between the community members and agency personnel were improved through the work of the community health advisers (CHAs). Respondents attributed the improvement in the quality of services as a result of feedback to agencies from the CHAs about client satisfaction as well as the extent to which community needs were met. In addition, the CHAs described increases in their ability to make changes in the agencies and institutions in their communities and cited examples where their actions had resulted in improved changes in service agencies.

In addition to influencing relationships between community institutions and communities with which they are working, political dynamics may also affect an evaluator's relationships with community members (Israel, Schulz, Parker, and Becker, 1998). Often socially and economically marginalized communities have not had the power to name or define their own experience in past research and evaluation activities. Recognition and acknowledgment of the inequalities between the evaluator and community participants and how these inequalities among community members may shape their participation and influence in program and evaluation activities will be useful for the evaluator in soliciting participation from community members (Israel, Schulz, Parker, and Becker, 1998). By including political dynamics in the definition of community, the evaluator is able to examine the extent to which influence is shared among health professionals and community members in defining solutions to community health concerns (Eng and Parker, 1994).

In considering the various definitions of a community in health program planning and evaluation, Steuart's conceptualization of units of identity and solution can be extremely useful. In Steuart's schema (1993), there are units of identity (units with which individuals feel themselves to be associated, such as relational communities) and units of solution (defined as units appropriate or essential for the solution of particular problems). Communities of identity may be centered on a defined geographic neighborhood or a geographically dispersed ethnic group with a sense of common identity and shared fate (Israel, Schulz, Parker, and Becker, 1998). For example, neighborhoods may be units of identity if the residents feel a sense of connection and belonging with each other, share needs and aspirations, and experience similar conditions. In any geographically defined city or county, there are likely to be many units of identity. These units of identity are potential units of solution if the members work together in collective problem solving. In addition, for the purposes of community problem solving, different units of identity may need to come together to form units of solution: that is, many units of identity may need to come together, pooling resources to forge a common solution to a problem or concern that they 
all share. For evaluators of community-based health programs seeking to increase community problem-solving capacity, this distinction means consideration of a community as more than a geographical entity. Identifying the units of identity of the community members involved in an intervention can allow the evaluator to track how these units of identity become units of solution and what partnerships have been formed among the various units of identity to become units of solution.

An example of consideration of both the relational elements and the political dynamics of a community in assessing units of identify and solution can be found in the East Side Village Health Worker Partnership. In this project, extensive consideration has been given to the historical and political context as well as the internal organization of the intervention area. Evaluators noted both strengths and challenges of the intervention area tied to historical events and political context (Parker, Schulz, Israel, and Hollis, 1998). For example, Detroit has traditionally had a large number of single-family households (which could serve as a base for a neighborhood organizing strategy), a history of union and neighborhood organizing, and relatively positive relationships between police and community residents on the east side since the 1970s. Yet Detroit also experiences challenges facing other urban areas, such as past racial tensions and out-migration of population and businesses. Consideration of these broad historical and political factors allowed the evaluators to understand the history and context within which the intervention developed and to examine the evaluation results, including changes in community capacity, in the light of these historical factors.

In addition, to ascertain how a carved-out geographical intervention area corresponded to the internal organization of the area, evaluation staff sought input from the Partnerships' Steering Committee (comprising community-based organization and agency representatives) and also conducted key informant interviews with community members. In these interviews, respondents were asked about their conceptualizations and perceived boundaries of their community, functions of their community, strengths and problems of their community, helping patterns, and history of communal activities. The results of these interviews indicated that residents described their neighborhoods as units of identity, spoke of strong neighborhood-based relationships, and described active block clubs, agency services, churches, and individuals. Respondents also identified neighborhood concerns such as drug dealers, lack of parenting skills, lack of supervised activities for children and youth, and violence.

From this information, evaluators, working with program participants, were able to identify existing units of identity and potential units of solution within the intervention area from which the program could build on in trying to strengthen community capacity. In addition, they were able to identify limits of the evaluation design, which focused on a geographic community with an imperfect match with communities of identity and solution. In doing so, the evaluators and community partners can examine the implications of these differences for the evaluation and intervention design, and discuss potential 
actions to strengthen the ability of the evaluation to document changes brought about through the intervention.

- Evaluators working in community settings should define community capacity through the blending of academic and community conceptualizations. Although there is no clear consensus on the conceptual or operational definition of community capacity, there are several similar constructs to community capacity, such as community competence (Cottrell, 1976; Eng and Parker, 1994), sense of community (McMillan and Chavis, 1986), and community empowerment (Wallerstein, 1992; Israel, Checkoway, Schulz, and Zimmerman, 1994). Each of the case examples in this chapter has used elements of these constructs in the operating definition of community capacity. In addition, to include consideration of the context of the community in which the program is operating, evaluators in each of these examples sought input from community members in confirming (and, if necessary, refining) their definitions of community capacity based on these constructs. Two examples of ways to engage the community in creating a context-specific definition of community capacity can be found in the PINAH project and the East Side Village Health Worker Partnership.

For the PINAH project, evaluators used Cottrell's framework on community competence as the basis to operationalize community capacity. To ensure a directly relevant definition of community competence, PINAH staff conducted two separate half-day workshops with two different community groups. The first group was the local Interagency Council, with representatives from all health and human service agencies in the county. The second group was a local community-based organization of African American leaders that emerged during the civil rights movement. In both workshops, PINAH staff led participants through a structured group exercise to arrive at a consensus on the characteristics they would look for to decide if a community "can get it together" (participants' term to describe community competence). The two groups generated twenty-three traits of a community that "could get it together." Staff then compared these twenty-three traits against Cottrell's eight dimensions of community competence, clustering those that corresponded to one of the dimensions and creating new dimensions from the remaining characteristics. The conclusion was that the twenty-three traits represented four dimensions of community competence-only three of Cottrell's eight dimensions and an additional dimension of social support. Because evaluation staff had no empirical basis for eliminating any of the dimensions (the five dimensions from the literature that were not mentioned by the service providers and community leaders and the new dimension of social support that was contributed by them), the evaluation took the more conservative decision of including all nine dimensions in the development of the community competence questionnaire (Eng and Parker, 1994). This questionnaire was then administered to key informants in each of the three communities.

Results of the baseline and three subsequent years of questionnaire administration supported Cottrell's assertion that community competence is a multidi- 
mensional construct. For example, although one of the three communities showed overall gains in the dimensions of participation, social support, commitment, and management of relations with the wider society, it saw no change in conflict containment and accommodation, articulateness, and self-other awareness. Results of the questionnaire administration also raised questions for the evaluators about the ability to capture community competence in a close-ended questionnaire accurately. From the qualitative interview data collected, the evaluation staff learned much about the context of the communities in which community competence was being measured. For example, in the qualitative data, many respondents spoke about racial conflict in some of the communities and how racism affected these communities' ability to solve problems around health and social issues. Because of the closed-ended nature of the questions asked on the questionnaire, none of these key findings arose in the questionnaire data.

In the East Side Village Health Worker Project, project staff developed an initial conceptual framework based on the stress literature of Israel and her colleagues (Israel, Checkoway, Schulz, and Zimmerman, 1994; House, 1981; Katz and Kahn, 1978). This framework postulates that stressors in an individual's environment contribute to an increase in perceived stress in the individual. This increase in perceived stress can then result in short-term responses to stress and strains that may contribute to enduring adverse health outcomes. In this case, the focus was on stressors that affected the health of women and children. Of importance in this conceptual model is the role of conditioning variables: individual and situational characteristics that can affect the process through which stressors are experienced as stressful and can affect the relationship of stressors to health outcomes. Conditioning variables can have a direct relationship to health status, a positive impact on health by buffering the effect of stress, a negative impact by amplifying its effect, or a neutral role. Among the conditioning variables in this conceptual framework of relevance to this discussion are community capacity, community empowerment, social support, accessible services, and existing local, state, and national policies.

To elaborate this framework for the context of the intervention area, project staff sought the input of the steering committee in identifying stressors and conditioning variables present in the East Side. University partners facilitated a group exercise with the steering committee in which members were asked to identify sources of stress for women who care for children on the East Side (stressors), how people feel and respond to these sources of stress (short-term responses to stress), what occurs if these stressors continue over a long time period (enduring health outcomes), and what the factors are that can keep these stressors from having a negative effect on people's lives (conditioning variables). The steering committee generated a list of forty-nine stressors and twenty-five conditioning variables (Schulz and others, 1998). This information was then used as a basis for developing a 350-item survey questionnaire. When conditioning variables identified by the steering committee members were similar to those identified in the literature (for example, sense of community, sense of control, neighbors helping neighbors), evaluation staff used 
already-existing items from these constructs. For the conditioning variables and stressors identified by the steering committee members with no similar constructs in the literature, evaluation staff developed new questionnaire items. Thus, evaluation staff blended knowledge from the literature with knowledge of community members to create a measurement tool that captures the context of East Side Detroit.

- Evaluators should use evaluation approaches that enhance community capacity. Evaluation methods for a program intending to increase community capacity should not contradict or interfere with the goals and values of the stated purpose (Eng and Parker, 1994). The choice of methods and process should facilitate the reciprocal transfer of knowledge, skills, capacity, and power (Israel, Schulz, Parker, and Becker, 1998). Methods that are participatory in nature and allow for the transfer of knowledge and skills between the evaluators and the program beneficiaries are encouraged. Evaluators need to give explicit attention to the knowledge of community members and emphasize sharing information, decision-making power, resources, and support among members of the intervention partnership (Israel, Schulz, Parker, and Becker, 1998). Fortunately, evaluators hoping to use a more participatory approach have a large literature spanning the social sciences that has examined approaches to research in which participants are actively involved in all aspects of the research process. Examples from this literature include participatory research, participatory action research, action research, action science/inquiry, cooperative inquiry, feminist research, participatory evaluation, and empowerment evaluation (Israel, Schulz, Parker, and Becker, 1998). Common elements of these approaches include the integration of knowledge and action for the mutual benefit of all partners in the evaluation process and conducting evaluation activities in a way that promotes a co-learning and empowering process for the intended program participants (Israel, Schulz, Parker, and Becker, 1998). For evaluators, this may mean offering technical assistance to coalition members on evaluation and other skills. For example, in the East Side Village Health Worker Partnership, academic partners responsible for the evaluation responded to community requests to conduct workshops on grant writing, meeting facilitation, and questionnaire interviewing for community-based organizations involved in the project.

- Active involvement of community members and service providers as partners is crucial in all components of the evaluation process. A key component of any evaluation seeking to measure community capacity or related concepts is the involvement of community members and service providers in all phases of the evaluation process, including the development of the initial evaluation plan, the conceptualization of community capacity, development of instruments and interview guides, and analysis and interpretation of the data (Israel, Schulz, Parker, and Becker, 1998; Fetterman, 1994).

Although finding ways to involve community members in these processes may be challenging at times due, for example, to project outcomes stipulated 
at the time of funding or short time lines, involvement of project beneficiaries in identifying what is to be evaluated and how it will be evaluated can enhance the quality of the evaluation itself, as well as serve as a capacity-building exercise for all partners involved in the project. The North Carolina CommunityBased Public Health Initiative evaluation was able to involve community partners in the development of the evaluation plans. Much of the first year of the project was devoted to developing the evaluation plans for each of these coalitions. The evaluation staff undertook twenty-two individual in-depth interviews and eight focus group interviews with members of each of the four coalitions. A semistructured interview guide was used, and respondents were asked "what they envisioned happening in the next four years as a result of the project" and "what would be the indicators to know that this change had happened." Results of the interviews were analyzed, and evaluation questions and indicators were identified from these interviews. Examples of indicators for one of the county coalition plans include number of registered and active voters, number of activities that health advisers are engaged in, number of agency employees undergoing cross-cultural competency training, and number of residents participating in community activities. Other indicator criteria were much more qualitative in nature, such as: "process is present for facilitating input from all community members in decision-making," "agencies give priority to problems identified by community," and "presence of organized minority health programs in health agencies."

Involving community members in the development of items for survey instruments is another important way to involve them in the evaluation process. In the East Side Village Health Worker Partnership, the steering committee was involved not only in identifying the stressors and conditioning variables used to create many of the items in the survey questionnaire, but also in decisions about the criteria to determine respondents; the recruitment, hiring, and payment of interviewers; and review of the survey instrument to suggest items to be added and deleted. (See Schulz and others, 1998, for a more detailed description of the process of developing and conducting the evaluation survey.)

One strategy for addressing the challenges of participation of all partners in the evaluation process is the joint development of some type of memorandum of understanding (Israel, Schulz, Parker, and Becker, 1998). For example, in both the East Side Village Health Worker Partnership and the Broome Team evaluations, a set of community-based public health research principles was adopted by all partners (Parker, Schulz, Israel, and Hollis, 1998; Schulz and others, 1998). The principles in use by the East Side Village Health Worker Partnership were adapted from ones earlier developed by the Detroit-Genesee County Community-Based Public Health Consortium (Schulz, Israel, Selig, and Bayer, 1998). They serve as guidelines to ensure that all research activities benefit the community and actively involve representatives of communitybased organizations, public health agencies, health care organizations, and educational institutions in all major phases of the research process. 
- The use of both qualitative and quantitative methods is important. Given the aims and the dynamic context within which community-based evaluation is conducted, methodological flexibility is essential; that is, the methods must be tailored to the purpose of the research and the context and interests of the community (Israel, Schulz, Parker, and Becker, 1998). One way to achieve this flexibility is through the use of both qualitative and quantitative methods. All four of the case examples described employ both types of data collection in their evaluation activities. Thus, these evaluations have been better able to capture the context and process, as well as the outcomes, of the interventions they are evaluating. For example, the PINAH project originally did not intend to collect qualitative data as part of the evaluation activities. But in Year 3 of the project, evaluators identified the need to incorporate qualitative interviews with residents, elected officials, community health advisers, providers, and project staff in order to amplify these respondents' perceptions and reactions about changes observed over the first four years of the project and to explain the level and direction of changes in community competence associated with the quantitative measures of health behaviors (such as service utilization) and agency collaboration (such as the pattern of referrals with community-based organizations) (Eng and Parker, 1994).

- A strong community-based evaluator will monitor participation in the evaluation process. Evaluations of capacity-building efforts can also contribute to monitoring, self-reflection, and modifications when necessary in the processes through which coalition members are working together. For example, a key component of the Broome Team evaluation was the development and use of the Broome Team Process Questionnaire. This instrument (adapted from an instrument developed by Israel, Schurman, Hugentobler, and House, 1992) was used to monitor collaboration among the members of the Broome Team coalition. Questions on the survey instrument asked respondents to assess their perceptions of ownership in the project, their own participation and that of others, the extent to which they felt they had influence in discussions and decision-making processes, the ability of the team to make effective decisions, and the extent to which team members felt that the Broome Team was effective in working toward change in their communities (Schulz, 1995).

Through the use of this instrument, the evaluator was able to assess how well the participatory principles of the project and the evaluation were being followed. Results from this survey were brought back to the Broome Team each year, and meeting time was set aside to discuss the results. Specific results from: these assessments (reported in more detail in Schulz, 1995) were generally. favorable in terms of team members' perceptions of trust and efficacy in working together. However, results were perhaps most useful as a process evaluation instrument that provided a catalyst for discussion among Broome Team members when presented as trend data, comparing results over time.

- Timely and appropriate feedback of data to all partners throughout the project is necessary for a community-based evaluation to be successful. Israel, Schulz, Parker, and Becker (1998) note that "community-based research seeks to 
disseminate findings and knowledge gained to all partners involved, in language that is understandable and respectful" (p. 180). Evaluations of community-based public health programs seeking to enhance community capacity need to do the same. Feedback of the evaluation data allows the evaluator to fulfill the requirement to be participatory in the evaluation approach. It also allows community members and service providers to discuss and interpret the evaluation data, a process that not only increases the capacity of all partners in the project but also enriches the understanding of the implications of the data results.

In the Broome Team evaluation, data from the evaluation were fed back to the team annually. Team members became engaged in the evaluation process and actively participated in discussion and interpretation of the data. As trend data became available (in Years 3 and 4 of the project), Broome Team members observed and discussed patterns in the data and used these to reflect on their own group process. For example, one year showed a drop in the generally high levels of trust reported among team members. In discussing this trend, the members identified a conflict that had emerged among members of the team in a different context, which then contributed to decreased trust within the team. Participants were able to discuss and problem-solve around this issue, and move forward in their working relationships as a result.

\section{Future Directions}

New conceptualizations of community capacity (Goodman and others, 1998; Parker and Eng, 1995) provide additional guidance for operationalizing community capacity for program and evaluation purposes. Yet much empirical work still needs to be done before evaluators know if it is possible to have one conceptual definition of community capacity and, if so, what that definition should be. However, even with these suggested new frameworks and possible future agreement on the definition of community capacity, there will always be a need to follow the participatory guidelines suggested here and to solicit community members' input in creating a vision of community capacity that is appropriate to the context of their community.

It is also important to note that the case examples here, unlike most funded health programs, were not focused on categorical diseases but rather on health broadly defined (or, in the example of the East Side Village Health Worker Partnership, the health of women and children). In addition, each of these interventions had increasing community capacity as one of its initial objectives. Projects funded to target categorical health problems may also benefit from the inclusion of intervention objectives and measures to evaluate community capacity as well as the use of more participatory methods to enhance community capacity of all project partners.

Currently, three of us are beginning interventions targeting categorical diseases. Two of us are involved with the intervention and evaluation of a household and neighborhood project seeking to reduce asthma triggers in children. 
A third is involved with the development and evaluation of a lay health adviser intervention that seeks to reduce sexually transmitted diseases in a rural county. Both projects plan to include qualitative and quantitative measures of community capacity as part of their evaluation activities. The experiences of these two projects, in comparison to the four case examples described in this chapter, will provide much-needed information on the challenges and successes associated with evaluating community capacity in relationship to a categorical focused health program.

\section{References}

Brownson, R. C., Riley, P., and Bruce, T. "Demonstration Projects in Community-Based Prevention." Journal \& Public Health Management and Practice, 1998, 4 (2), 66-77.

Cottrell, L. S. "The Competent Community.' In B. H. Kaplan, R. N. Wilson, and A. H. Leighton (eds.), Further Explorations in Social Psychiatry. New York: Basic Books, 1976.

Eng, E., and Parker, E. "MeasuringCommunity Competence in the Mississippi Delta: Interface Between Program Evaluation and Empowerment."Health Education Quarterly 1994, 21 (2), 199-220.

Eng, E., Salmon, M., and Mullan, F. "Community Empowerment:The Critical Base for Primary Health Care." Family and Community Health, 1992, 15 (1), 1-2

Eng, E., and others. "Community Coalition Structures for Capacity Building: Results from the NC Community-Based Public Health Initiative." Unpublished manuscript.

Fetterman, D. M. “EmpowermentEvaluation.”Evaluation Practice, 1994, 15(1), 1-15.

Goodman, R. M., and others. "Identifying and Defining Dimensions of Community Capacity to Provide a Basis €orMeasurement." Health Education and Behavior, 1998, 25 (3), 258-278.

Goeppinger, J., and Baglioni, A.J. "Community Competence: A Positive Approach to Needs Assessment." American Joumal of Community Psychology, 1985, 13 (5), 507-523.

Heller, K. "The Return to Community."American Journal of Community Psychology, 1989, $17,1-15$.

House, J. S. Work Stress and Social Support. Reading, Mass.: Addison-Wesley, 1981.

Institute of Medicine. The Future of Public Health. Washington, D.C.: National Academy Press, 1988.

Israel, B. A., Checkoway, B., Schulz, A .J., and Zimmerman, M. A. "HealthEducation and Community Empowerment: Conceptualizing and Measuring Perceptions of Individual, Organizational, and Community Control." Health Education Quarterly, 1994, 20 (2), 149-170.

Israel, B. A., Schulz, A. J., Parker, E. A., and Becker, A. B. "Community-Based Research: A Partnership Approach to Improve Public Health.”Annual Review of Public Health, 1998, 19, 173-202.

Israel, B. A., Cummings, M. Dignan, M, B., Heaney, C. A., Perales, D. P., Simons-Morton, B. G., and Zimmerman, M. A. "Evaluation of Health Education Programs: Current Assessment and Future Directions."Health Educahon Quarterly, 1995, 22, 364-389.

Israel, B. A., Schurman, S. J., Hugentobler, M. K., and House, J. S. "A Participatory Action Research Approach to Reducing Occupational Stress in the United States." In V. DiMartion (ed.), Preventing Stress at Work: Conditions of Work Digest (Vol. 2). Geneva: International Labour Office, 1992.

Katz, D., and Kahn, R. The Social Psychology of Organizations. New York Wiley, 1978.

W. K. Kellogg Foundation, "Grantmaking Initiative Announcement for Community-Based Public Health." In-house document, 1990.

LaBonte, R. "Community Empowerment: The Need for Political Analysis." Canadian Journal of Public Health, 1989, 80, 87-88. 
McKnight, J. Unpublished comments Made at Leadership and Model Development Meeting for Community-Based Public Health Initiative. Chicago: W. K. Kellogg Foundation, 1991. McMillan, D., and Chavis, D. "Sense of Community: A Definition and Theory." Journal of Community Psychology, 1986, 14, 6-23.

Parker, E. A., and Eng, E. "ConceptualizingCommunity Problem-Solving Capacity: Results of a Grounded Theory Study."Unpublished paper, University of Michigan, 1995.

Parker, E. A., Schulz, A. J., Israel, B. A., and Hollis, R. "East Side Detroit Village Health Worker Partnership: Comrnunity-Based Lay Health Adviser Intervention in an Urban Area." Health Education and Behavior, 1998, 25 (1), 24-45.

Parker, E. A., and others. "Coalition Building for Prevention: Lessons Learned from the North Carolina Community-Based Public Health Initiative." Journal of Public Health Management and Practice, 1998, 4 (2), 25-36.

Sampson, R. J., Raundenbush, S. W., and Earls, F. "Neighborhoods and Violent Crime: A Multilevel Study of Collective Efficacy."Science, 1997,277, 1997,918-974.

Schulz, A. J. Broome Team Evaluation Report. Detroit Genesee County Community Based Public Health Project, Aug. 1994-Aug. 1995.

Schulz, A. J., Israel, 3. A., Selig, S. M., and Bayer, I. S. "Developmentand Implementation of Principles for Community-Based Research in Public Health.” In R. H. MacNair (ed.), Research Strategies for Community Practice. New York: Haworth Press, 1998.

Schulz, A. J., and others. "Conducting a Participatory Community-Based Survey: Collecting and Interpreting Data for a Community Health Intervention on Detroit's East Side." Journal of Public Health Management and Practice, 1998, 4 (2), 10-24.

Steckler, A., Dawson, L., Israel, B., and Eng, E. "Community Health Development: An Overview of the Works of Guy W. Steuart."Health Education Quarterly, 1993, Supplement 1, s3-s20.

Steuart, G. W. "Socialand Behavioral Change Strategies."Health Education Quarterly, 1993, Supplement 1,sl13-135.

Trostle, J. "Anthropology and Epidemiology in the 20th Century: A Selective History of Collaborative Projects and Theoretical Affinities, 1920-1970." In C. Janes and others (eds.), Anthropology and Epidemiology. Boston: Reidel Publishing Co., 1986.

Wallerstein, N. "Powerlessness, Empowerment, and Health: Implications for Health Promotion Programs." American Journal of Health Promotion, 1992, 6 (3), 197-205.

Warren, R. B., and Warren, D. I. The Neighborhood Organizer's Handbook. Notre Dame, Ind.: University of Notre Dame Press, 1977.

EDITH A. PARKER is assistant professor of health behavior and health education at the University of Michigan School of Public Health.

EUGENIA ENG is associate professor and director of the master of public health degree program in the Department of Health Behavior and Health Education in the School of Public Health at the University of North Carolina at Chapel Hill.

AMY J. SCHULZ is assistant research scientist in the Department of Health Behavior and Health Education, and associate directorfor qualitative researchfor the Center on Ethnicity, Culture and Health at the University of Michigan School of Public Health.

BARBARA A. ISRAEL is professor and chair in the Department of Health Behavior and Health Education at the School of Public Health, University of Michigan. 